\title{
RESPONSABILIDADE SOCIAL E ANÁLISE COMPARATIVA ENTRE DUAS INSTITUIÇÕES FINANCEIRAS
}

\section{ARTIGO ORIGINAL}

POTAS, Alberto Veiga ${ }^{1}$

POTAS, Alberto Veiga. Responsabilidade social e análise comparativa entre duas instituições financeiras. Revista Científica Multidisciplinar Núcleo do Conhecimento. Ano 04, Ed. 05, Vol. 07, pp. 186-209. Maio de 2019. ISSN: 2448-0959.

\section{RESUMO}

Nesta pesquisa o tema de responsabilidade social tem como objetivo apresentar e conhecer como se deve analisar empresas nos relatórios anuais de balanço social. $O$ objetivo é investigar a importância e utilidade que tem a responsabilidade social para empresas localizadas no Brasil, mostrando as ações das organizações com o intuito de identificar e verificar dados, informações, e quais os projetos realizados e problemas existentes. Para isso será necessário realizar uma pesquisa bibliográfica teórica, investigando a relação das empresas com a comunidade local, seguindo o conceito de responsabilidade social dentro dos limites éticos e morais. É necessário conhecer quais instituições realizam projetos e como eles são feitos através das observações dos resultados, será analisado também se este procedimento proporciona um desenvolvimento sustentável eficiente dentro da região.

Palavras-chave: Responsabilidade social, desenvolvimento sustentável, gestão de empresas, sustentabilidade, balanço social.

\section{INTRODUÇÃO}

\footnotetext{
${ }^{1}$ MBA em Gestão Estratégica e Empresarial - USCS - Universidade do Município de São Caetano do Sul E Bacharelado em Administração de empresas - UNIABC Universidade do Grande ABC.
} 
O trabalho aborda um tema de grande relevância no meio empresarial: a responsabilidade social.

A discussão tem se tornado cada vez mais frequente, visto que o mesmo é constantemente veiculado pelas organizações por meio de diversas mídias, bem como no meio acadêmico.

O Objetivo principal é apresentar o tema de forma que compreenda a finalidade, história e conceito, podendo entender de maneira eficiente a teoria e a aplicação de um relatório anual de balanço social de duas instituições financeiras.

Em específico, definir os elementos importantes do tema adquirindo conhecimento sobre o âmbito da responsabilidade social e sustentabilidade, aprender analisar um balanço social de uma empresa e compará-la com outras empresas com uma visão detalhada da análise das informações dos resultados em seus relatórios.

O capítulo 1 apresenta a metodologia do trabalho conforme Severino (2007). O assunto é baseado na pesquisa exploratória e bibliográfica.

Já o capítulo 02 introduz o assunto no estudo que aborda o tema na teoria e na história, incluindo a visão técnica e analítica dos resultados de cada instituição que se importa com o ambiente em que se relaciona.

O capítulo 3, 4 e 5 trata do referencial teórico que serve de base para o estudo. Ao unir os conceitos com a prática definindo os elementos, os fatos personagens e instituições principais, é ampliado o conhecimento do tema a história empregada na análise de outras obras registradas.

No capítulo 06 é demonstrado a apresentação das empresas inseridas nesta pesquisa com seu contexto histórico e analítico, conhecendo os aspectos de política corporativa de cada instituição e o seu papel com a responsabilidade social.

O capítulo 07 realiza a análise de resultados do balanço social de duas empresas no ano de 2013 e 2014, mostrando a comparação entre indicadores. 
Por fim, o capítulo 08 trata-se das considerações finais, sugerindo a ampliação de novas pesquisas para outras áreas do conhecimento tendo o auxílio de uma abordagem pedagógica.

\section{MÉTODO}

Este trabalho foi baseado em pesquisa bibliográfica na área e tema de responsabilidade social e sustentabilidade. Com discurso de alguns autores como referência e estudo exploratório, proporcionando maiores informações sobre o assunto e descobrindo um novo enfoque baseado em informações de fontes confiáveis, autores, revistas e artigos que auxiliaram na construção e resolução deste trabalho.

\section{OBJETIVOS DO DESENVOLVIMENTO DO MILÊNIO (ODS)}

A ONU (Organização das ações Unidas) promoveu um debate no ano de 2000, reunindo chefes de Estados e Governos para estabelecerem metas ao longo dos anos 90, com o objetivo de desenvolverem meios para a erradicação da pobreza no mundo. Esta ideia deveria ser alcançada até o ano de 2015.

Foram criados 8 objetivos com 18 metas e 48 indicadores, sendo que estes objetivos deveriam considerar especificações nacionais. Alguns países estão abaixo de seu limite, não tendo capacidade para alcançar meios de desenvolvimento.

Os oito objetivos identificados foram:

1. - Erradicação da extrema pobreza e a fome.

2. - Atingir o ensino básico universal.

3. - Promoção da igualdade de gênero e a autonomia das mulheres.

4. - Redução da mortalidade infantil.

5. - Melhora da saúde materna.

6. - Combate ao HIV / AIDS, a malária e outras doenças.

7. - Garantia da sustentabilidade ambiental.

8. - Estabelecimento de uma parceria mundial para o desenvolvimento. 
Assim os Objetivos de Desenvolvimento do Milênio (ODM) considera a erradicação da pobreza, fome e analfabetismo, igualdade de gênero e sustentabilidade ambiental.

Entre 1990 e 2010 a extrema pobreza foi reduzida de $47 \%$ para $22 \%$ da população mundial, na qual a meta foi atingida. Entretanto, 1,2 bilhão de pessoas ainda estão na extrema pobreza do mundo (recebendo menos de US\$1,2 por dia). O acesso à educação e à saúde está evoluindo no mundo todo, assim como avançam as ações de proteção ao meio ambiente. No Brasil os resultados dos ODM, são extremamente positivos, o intuito é alcançar ou superar estas metas.

Após a implantação dessa ideia e resultados, as metas foram sendo incorporadas dentro das empresas, gerando uma transformação em seu modo de gerenciar e interagir com a sociedade.

\section{BREVE HISTÓRICO DA RESPONSABILIDADE SOCIAL}

\section{NO MUNDO}

Nos últimos anos da década do século 20, a consciência de humanidade trouxe consigo novas maneiras comportamentais para sociedade, empresas e governos. Formas de pensar e agir, sendo a globalização de forma acelerada. O acontecido trouxe mudanças com novas situações e condições para o mundo.

O mercado mundial aumentou devido as novas tecnologias de transporte aéreo, marítimo e terrestre.

Os meios de comunicações e informações evoluíram de forma tecnológica. A internet foi a ferramenta que conectou e aproximou o mundo, criando redes globais e aumentando a potência de relações entre culturas, países, empresas e mercados.

Ao mesmo tempo aumentava a concorrência entre empresas de diversos países, um exemplo disso foi a concorrência entre Estados Unidos e Japão, que deu origem ao tecido Nylon: "Now you've loose, old Nippon." 
A globalização gerou grandes oportunidades de negócios, por outro lado o aumento da pobreza e exclusão. Enquanto alguns países estavam avançados em relação à sua economia, outros eram marginalizados. Um exemplo dessa situação está na área da educação em plena era da informação, enquanto alguns países se modernizam com computadores, outros sofrem com a falta de condições, por exemplo, materiais escolares e um local bem estruturado para estudo.

A reestruturação das empresas na época, levaram ao fechamento de instalações em países com mão de obra barata, fazendo com que instituições desenvolvidas encerrassem as atividades dentro das comunidades, deixando países carentes e agredindo o meio ambiente com o uso indiscriminado da matéria prima. O ocorrido contribuiu excessivamente com o superaquecimento do planeta, poluição dos rios e mares, e o desperdício de lixo em grande quantidade.

As empresas eram voltadas apenas para as atividades econômicas e produtivas, sem se preocupar com impacto social, ambiental e o desenvolvimento do futuro.

A ideia do Desenvolvimento sustentável foi consagrada no maior encontro já realizado para se discutir o futuro do planeta, Conferência das Nações Unidas sobre o meio ambiente e desenvolvimento. A ECO-92, que foi realizada no Rio de Janeiro MARTINS (2011).

(NOVAES, 1992, pg. 80) complementa que:

“[...]pensar que o ator principal na questão das mudanças climáticas aceitasse o papel que the cabia - o da maior quota na redução da emissão de poluentes atmosféricos, que contribuem para o cenário em que se discutem as mudanças."

O Desenvolvimento sustentável é aquele que gera conhecimento econômico, preocupa-se com impacto ambiental e está voltado para o desenvolvimento da comunidade, chamado Triple Bottom Line (a união dos três p's: People, Profit, Planet, traduzindo pessoas, negócios e planeta) 
Para discutir rumos da globalização, governos, setores empresarias e ONG's se reuniram em conferências no Ciclo Social das Organizações das Nações Unidas no início dos anos 90. Este encontro foi realizado para que fosse possível rever ações e criar objetivos do Desenvolvimento do Milênio (ODM), conhecidos como metas do milênio. Em 2000, 191 países assumiram compromisso com as metas, e em 2015, 193 países.

\section{NO BRASIL}

Sabe-se ao certo que o início da história da responsabilidade social no Brasil tinha registros em ações sociais de empresários desde o século XIX, pode-se também indicar o ano de 1965 como um dos marcos iniciais desse tema. Como contexto havia eminentes desníveis econômicos e o enorme atraso de certas áreas do país decorrentes, em parte de não ter o setor empresarial tomado plena consciência de suas responsabilidades sociais, diante deste cenário, a ADCE Brasil (Associação de Dirigentes Cristão de Empresas) publica a "Carta de Princípios dos Dirigentes Cristãos de Empresas". O documento chama o empresário para entender que a "atividade empresarial não deve absorver o empresário, nem transformar o fim em si mesma, pois o dirigente de empresa tem obrigação de participar ativamente e com plena responsabilidade na vida cívica e política da comunidade". (FREIRE, 2001)

"O marco da responsabilidade social no Brasil se deu mais precisamente em 1965, com a publicação da Carta de Princípios do Dirigente Cristão de Empresas, que já nesta época, utilizava o termo responsabilidade social das empresas. Contudo, foi somente a partir dos anos 80 que pequena parcela das empresas que atuam no Brasil passara a intensificar e a institucionalizar o discurso em relação às questões sociais e ambientais, realizando também em escalas diversificadas ações sociais concretas." (FREIRE, 2001, pg.54)

A partir desse ponto houve grande mobilização em relação ao tema e à situação. 
Criaram prêmios, debates, espaços, práticas, institutos, fundações, comitês e propagação de balanços sociais, na qual hoje existem técnicas avançadas de relatórios anuais de sustentabilidade com grandes números de páginas e informações detalhadas sobre planos e ações das empresas.

Nos anos 80, a primeira empresa a apresentar seu balanço social, foi a Nitrofértil, em 1984 na qual sem a padronização atual foi feita como literatura de cordel.

A década de 1990 marcou o período do surgimento e da consolidação de diversas organizações que se institucionalizaram para promover o tema da responsabilidade social empresarial. Foi quando o amadurecimento da ideia de "responsabilidade social das empresas" e da necessidade de realização e publicação de balanço social anual na cultura das organizações empresariais brasileiras sofreu diversas influências nacionais e internacionais.

Um personagem muito importante neste debate foi Herbert José de Souza, conhecido como Betinho, sociólogo e ativista dos direitos humanos, responsável por fundar a ADCE Brasil (Associação de Dirigentes Cristão de Empresas) onde a publicação da Carta de Princípios do Dirigente Cristão de empresas chama o empresariado à entender que a atividade não deve ser voltada a si mesma, mas para comunidade e sociedade:

"Deve replicar com a ação positiva e fecunda de quem oferece, em contraposição, o senso de responsabilidade dos dirigentes de empresa cônscios dos seus deveres sociais de cristãos e dispostos a lutar unidos por uma ordem social mais justa, por uma ordem econômica a serviço do homem, por um desenvolvimento integral e harmônico" (Carta De princípios do dirigente cristão de empresa 1967, pg.1).

Com a criação do IBASE (Instituto Brasileiro de Análises Sociais e Econômicas), foi transmitido a importância de divulgarem seus balanços sociais, sendo padronizado o documento para transparência e informação dos projetos voltados aos empregados, investidores e comunidade. 
Atualmente é preciso compreender que, como qualquer outra organização, as empresas têm uma história evolutiva e mudam com relativa frequência. Atuam em um ambiente com qual se relacionam de muitas formas, impactando e sendo impactados por tudo que lhes cercam, tendo como dever construir novos atores e cenários sociais integrandos a sociedade.

\section{O CENÁRIO ATUAL DA RESPONSABILIDADE SOCIAL NO BRASIL}

O Brasil é o 75ํㅜ pais em posição referente ao IDH Global com 0,755 em 2014, com número de população de 206.081 .432 habitantes, $47,73 \%$ de brancos, $50,74 \%$ de negros e com índice de pobreza com 2,8. Com tamanho territorial de 8.514.876,599 $\mathrm{km}$, representando o segundo maior país do continente americano, atrás dos Estados Unidos

Segundo OLIVEIRA (2002), existe uma carência de serviços sociais básicos no Brasil que afeta uma grande parte da população. O país sofre devido a uma série de problemas sociais como: desigualdade de renda, baixa qualidade na educação, trabalho infantil, analfabetismo persistente, uma das mais altas taxas de acidente de trabalho, mortalidade infantil elevada em algumas regiões, violência contra a mulher etc. Portanto, há muito espaço para as organizações atuarem.

Em 2001 a Revista Administração revela que mais de 50\% das empresas brasileiras realizam algum tipo de atuação social. Alguns temas sociais como minorias étnicas, portadores de vírus HIV, dependentes químicos, pessoas com deficiência, ficam geralmente relegados ao apoio de uma pequena parcela do esforço empresarial. Também parece haver uma correlação entre tamanho da empresa e voluntariado, as empresas maiores estão mais envolvidas e organizadas do total de empresas no Brasil, em 2004 IPEA (2006) a maioria se localizava no Sudeste (48\%) e no Sul (30\%), com menor participação do Nordeste (9\%) e do Centro-Oeste (9\%), além do Norte (4\%). Por sua vez, apresentavam maior quantidade de empresas os setores de comércio $(53 \%)$ e serviços $(24 \%)$. Já no que se refere ao porte, observa-se que, quanto maior o número de empregados, menor o número de empresas, ou seja, há mais empresas na categoria micro (até 10 empregados), seguida da pequena (de 11 
a 100 empregados) e depois da média (101 a 500 empregados) e da grande (mais de 500 empregados), com participação 421 de $71 \%, 22 \%, 3 \%$ e 1\%, respectivamente.

Os dados do IPEA (2006) indicam um crescimento significativo (de 59\%, em 2000, para $69 \%$, em 2004) na proporção de empresas privadas brasileiras que realizaram ações sociais em benefício das comunidades. Estima-se que aproximadamente 600 mil empresas atuam voluntariamente, considerando o universo de 871 mil empresas formais no Brasil

\section{RESPONSABILIDADE SOCIAL}

\section{DEFINIÇÃO}

O conceito de Responsabilidade Social Empresarial traz a questão da relação da empresa com seus diversos públicos de interesse, conforme expresso na definição do Instituto Ethos:

"Responsabilidade social empresarial é a forma de gestão que se define pela relação ética e transparente da empresa com todos os públicos com os quais ela se relaciona e pelo estabelecimento de metas empresariais compatíveis com o desenvolvimento sustentável da sociedade, preservando recursos ambientais e culturais para as gerações futuras, respeitando a diversidade e promovendo a redução das desigualdades sociais" (Instituto_Ethos,_2010,_on-line).

A Responsabilidade Social Empresarial geralmente envolve a busca de novas oportunidades como uma maneira de responder às demandas ambientais, sociais e econômicas do mercado. Dentro do conceito de Responsabilidade Social Empresarial que vem sendo incorporado pelas empresas, o público alvo deixa de ser apenas o consumidor e passa a abranger um número muito maior de pessoas e empresas influenciadas pelas atuações da organização. Essa Responsabilidade Social faz parte do desenvolvimento sustentável, o qual é composto pelas dimensões econômica, ambiental e empresarial, contribuindo assim para a melhoria de qualidade de vida da 
sociedade. Uma apresentação deste conceito é a definição apresentada por BARBOSA\&RABAÇA:

"A responsabilidade Social nasce de um compromisso da organização com a sociedade, em que sua participação vai mais além do que gerar empregos, impostos e lucros. O equilíbrio da empresa dentro do Ecossistema social depende basicamente de uma atuação responsável e ética em todas as frentes, em harmonia com o equilíbrio ecológico, com o crescimento econômico e com o desenvolvimento social." BARBOSA\&RABAÇA (2001 apud. TENÓRIO, 2006, p.25):

A empresa inserida neste conceito, será mais participativa com a sociedade sendo mais completa a sua função, além do papel econômico que exerce. Assim, ampliando a sua atuação e ao mesmo tempo valorizando-a como agente de transformação.

A Responsabilidade Social envolve alguns tópicos, OLIVEIRA (2002):

- Visão e Missão;

- Ética;

- Práticas gerais de recursos humanos;

- Relações de trabalho/sindical;

- Saúde;

- Relacionamento com cadeia produtiva;

- Relação com acionista;

- Práticas de mercado;

- Atendimento ao consumidor;

- Marketing social;

- Balanço social;

- Relação com governo;

- Meio ambiente;

- Ações culturais;

- Apoio à comunidade e;

- Direitos humanos. 
Com as competências básicas e responsabilidade social, as empresas adquirem o respeito das comunidades e consumidores que influenciam nas suas atividades, aumentando o reconhecimento para todos os colaboradores que resultam em uma vantagem competitiva para própria organização, valorizando sua marca, imagem e dando maior credibilidade.

\section{A POLÍTICA DE RESPONSABILIDADE SOCIAL}

Segundo MARTINS (2008), a empresa focada em desempenhar como uma organização socialmente responsável em termos sociais e ambientais, mobilizada para o ideal da sustentabilidade tem como um de seus grandes desafios escrever um documento, a Política de responsabilidade social e ambiental, conhecida como RSA.

Seguindo em princípios de ética, e suas ações é escrito com base e inspirada na sua própria raiz estratégica empresarial, com perspectiva e foco em relação a seus públicos:

- Fornecedores

- Clientes

- Consumidores

- Meio ambiente

- Comunidade

- Governo e sociedade em geral

E baseado nesses elementos a empresa direciona seus princípios, incluindo obrigatoriamente na sua estratégia:

- Missão da empresa: Descrição do compromisso da empresa com seus colaboradores e sociedade oferecendo serviços e aumentando o seu valor.

- Visão: Relacionado à sua área de atuação, apresenta seu objetivo e propósitos

Valores: realização nas práticas e ações que demonstram que comportamento tem â sociedade. Algumas delas como Qualidade, Confiança, Excelência, Segurança, respeito e Justiça 
- Código de ética: Baseado na Missão, visão e valores, é o conjunto da postura e a forma como a organização atua. Sendo a base para saber se a imagem está em conformidade com a identidade própria, ajudando na forma da resolução de momentos de impasse e crise.

\section{A POLÍTICA DE RESPONSABILIDADE SOCIAL E SUA ATUAÇÃO}

Em um relatório anual a empresa expressa todas as suas ações, objetivos e filosofia demonstrando o seu valor perante sociedade.

Incluso à missão, visão, valores estão designados também todos os investimentos em projetos em cada área de seu público. No qual a demonstração financeira destes se mostra o balanço social da empresa, dividindo seus projetos em quatro aspectos, entre eles:

- Colaboradores: inclusão de portadores de deficiência, de aprendizes, de terceira idade, plano de carreiras, ambiente positivo no trabalho, valorização da diversidade e CIPA's

- Meio ambiente: tecnologias para economia de água, evitar desperdício de copos plásticos, reutilização de papeis como rascunhos, campanhas de plantio de arvores e seleção de lixo.

- Comunidade: Investimento em educação e arte, organização de festas para arrecadação de fundos com destinação social, ajudar a distribuir comidas e roupas para moradores de rua,

- Sociedade: redução de trabalho infantil, cooperação entre Ong's e sindicatos, ajudar em projetos de educação, palestras sobre temas sustentáveis e voluntariado de ações sociais.

\section{BALANÇO SOCIAL}

A propósito deste relatório é definido por Luca (1998 p.32):

“[...] atender às necessidades de informações dos usuários da contabilidade, no campo social. É um instrumento de medida que permite 
verificar a situação da empresa no campo social, registrar as realizações efetuadas neste campo e principalmente avaliar as relações ocorridas entre o resultado da empresa e a sociedade"

Uma das formas da empresa demonstrar a sua atuação social é através da publicação do balanço social.

É uma demonstração que é apresentada junto com o balanço financeiro da empresa anualmente. Nela apresenta as informações como descrição do perfil de empreendimento, o setor econômico onde atua, histórico da empresa, estrutura, princípios, valores, missão e políticas.

O conteúdo do balanço está expresso em seus indicadores, como indicador social, interno, externo, ambiental, estrutura e de responsabilidade social. Sendo as informações voltadas para a empresa e os colaboradores, meio ambiente, comunidade e sociedade.

Algumas empresas, analisando o retorno que se tem ao aplicar esses conceitos e com seus resultados, investem em marketing social, pois aumentam o reconhecimento, lucram com o a marca e a imagem através das notícias veiculadas. Mas o importante é o reconhecimento interno, pois é o que motiva funcionários por estarem envolvidos com causas sociais, sendo um divulgador da empresa. E umas das formas é a implantação do Norma SA8000. OLIVEIRA, (2012)

Conforme O Balanço Social e a Comunicação da Empresa com a Sociedade 5ed, pag.20, o quadro apresenta fatores que apresentam a participação da empresa nas questões sociais como mostrada abaixo:

Quadro 1 - Modelo de Balanço Social apresentado pelo Instituto Ethos 
Demonstrativo do modelo lbase

\begin{tabular}{|c|c|c|c|c|c|c|}
\hline 1) Base de Cálculo & \multicolumn{3}{|c|}{2006 Valor (Mil reais) } & \multicolumn{3}{|c|}{2005 Valor (Mil reais) } \\
\hline \multicolumn{7}{|l|}{ Receita liquida (RL) } \\
\hline \multicolumn{7}{|l|}{ Resultado operacional (RO) } \\
\hline \multicolumn{7}{|l|}{ Folha de pagamento bruta (FPB) } \\
\hline 2) Indicadores Sociais Internos & $\begin{array}{l}\text { Valor } \\
\text { (mil RS) }\end{array}$ & $\begin{array}{l}\text { Qb sobre } \\
\text { FPB }\end{array}$ & $\begin{array}{l}\text { \%o sobre } \\
\text { RL }\end{array}$ & $\begin{array}{l}\text { Valor } \\
\text { (mil RS) }\end{array}$ & $\begin{array}{l}\text { \%o sobre } \\
\text { FPB }\end{array}$ & $\begin{array}{c}\text { To sobre } \\
\text { RL }\end{array}$ \\
\hline \multicolumn{7}{|l|}{ Alimentação } \\
\hline \multicolumn{7}{|l|}{ Encargos socials compulsórios } \\
\hline \multicolumn{7}{|l|}{ Previdência privada } \\
\hline \multicolumn{7}{|l|}{ Saúde } \\
\hline \multicolumn{7}{|l|}{ Segurança e saúde no trabalho } \\
\hline \multicolumn{7}{|l|}{ Educaçilo } \\
\hline \multicolumn{7}{|l|}{ Cultura } \\
\hline \multicolumn{7}{|l|}{$\begin{array}{l}\text { Capacitaçåo e desenvolvimento } \\
\text { profissional }\end{array}$} \\
\hline \multicolumn{7}{|l|}{ Creches ou auxilio-creche } \\
\hline \multicolumn{7}{|l|}{ Participaçâo nos lucros ou resultados } \\
\hline \multicolumn{7}{|l|}{ Outros } \\
\hline \multicolumn{7}{|l|}{ Total - Indicadores sociais internos } \\
\hline 3) Indicadores Sociais Externos & $\begin{array}{l}\text { Valor } \\
\text { (mil RS) }\end{array}$ & $\begin{array}{l}\text { \%b sobre } \\
\text { RO }\end{array}$ & $\begin{array}{l}\text { \%o sobre } \\
\text { RL. }\end{array}$ & $\begin{array}{l}\text { Valor } \\
\text { (mil RS) }\end{array}$ & $\begin{array}{c}\text { \% sobre } \\
\text { RO }\end{array}$ & $\begin{array}{l}\text { \%o sobre } \\
\text { RL }\end{array}$ \\
\hline \multicolumn{7}{|l|}{ Educaçầo } \\
\hline \multicolumn{7}{|l|}{ Cultura } \\
\hline \multicolumn{7}{|l|}{ Saúde e saneamento } \\
\hline \multicolumn{7}{|l|}{ Esporte } \\
\hline \multicolumn{7}{|l|}{ Combate à fome e segurança alimentar } \\
\hline \multicolumn{7}{|l|}{ Outros } \\
\hline \multicolumn{7}{|l|}{ Total das contribuiçôes para a sociedade } \\
\hline \multicolumn{7}{|l|}{ Tributos (excluidos encargos sociais) } \\
\hline Total - Indicadores sociais externos & & & & & & \\
\hline
\end{tabular}




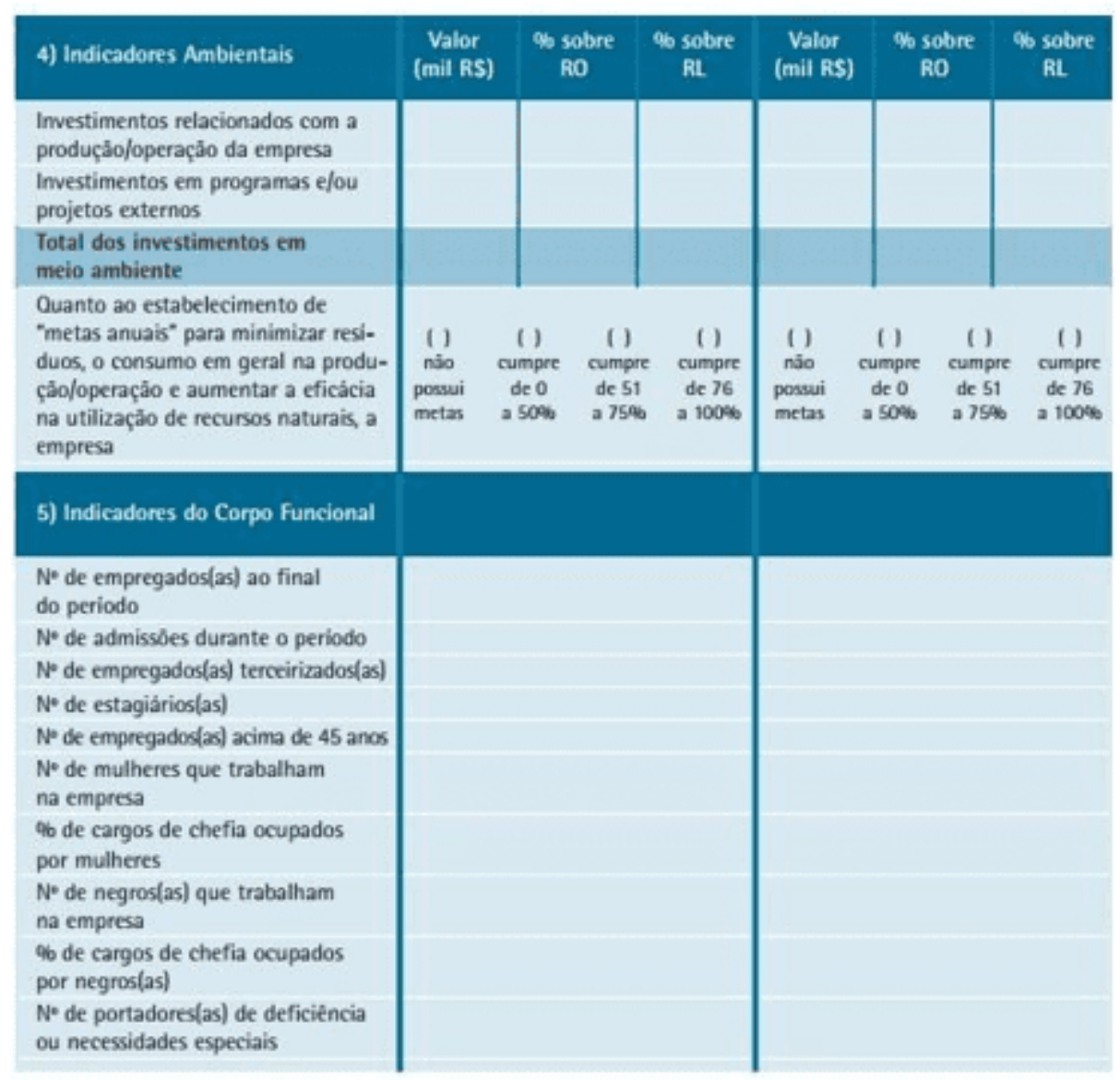

Fonte: Ethos

O modelo proposto pelo IBASE deve conter as seguintes informações:

1. - Base de Cálculo: informações que correspondem à receita líquida; o resultado operacional apresentado pela organização e a folha de pagamento bruta contabilizada no período.

2. - Indicadores Sociais Internos: informações relacionadas a ações sociais da empresa realizadas em conjunto com seus colaboradores (alimentação, previdência privada, saúde, educação, cultura, capacitação e desenvolvimento profissional, creche ou auxílio-creche, participação nos lucros ou resultados, entre outros benefícios).

3. - Indicadores Sociais Externos: informações que correspondem a ações sociais da empresa exercidas em parceria com a sociedade (reúne o total das contribuições em prol da sociedade mais os tributos, sendo destes excluídos os encargos sociais). 
4. - Indicadores Ambientais: informações operacionais da empresa que envolvam o meio ambiente, ou seja, quanto foi investido para recuperar o que por ela foi prejudicado. Esses 7 investimentos referem-se a projetos externos como despoluição, conservação de recursos ambientais, campanhas ecológicas, bem como investimentos para melhoramento contínuo da qualidade ambiental na produção da empresa, como por exemplo, gastos com introdução de métodos não-poluentes, auditorias ambientais, entre outros.

5. - Indicadores do Corpo Funcional: informações sobre funcionários (número de mulheres atuantes na empresa, número de negros, número de estagiários, número de empregados contratados acima de 45 anos, entre outros indicadores do corpo funcional).

6. - Informações relevantes: quanto ao exercício da cidadania empresarial e um questionário relacionado à participação dos funcionários no que diz respeito a ações de responsabilidade social conduzidas pela empresa.

7. - Outras Informações: este espaço está disponível para que a empresa agregue outras informações importantes quanto ao exercício da responsabilidade social, ética e transparência.

Em relação ao trabalho voluntário, segundo Rosa Maria Fischer e Andrés Pablo Falconer (2001, p.5) em Voluntariado empresarial - estratégias de empresas no Brasil.

"A maioria das empresas que consolidaram sua atuação social constituiu um instituto ou uma fundação, como forma jurídica e organizacional mais adequada para gerir as atividades. Estão nesse caso, na amostra estudada, o Instituto C\&A, o Instituto Credicard, a Fundação lochpe, a Fundação Victor Civita, a Fundação Educar e a Fundação Acesita. Enquanto Natura, Xerox, Avon, Informare, Dixtal, Bosch, McKinsey, Caixa Econômica Federal, Intermédica, 3M, Andersen Consulting e Schering-Plough são empresas que mantêm as atividades sociais no próprio âmbito da organização." FISCHER\& FALCONER (2001, p.5)

Assim muitas instituições e fundações voltadas à responsabilidade social no Brasil são mantidas e administradas por multinacionais ou empresas nacionais, como as citadas 
acima, podendo ser encontradas também, as informações no Instituto de pesquisa, promoção e fiscalização da responsabilidade social.

\section{APRESENTAÇÃO DAS EMPRESAS PESQUISADAS}

\section{BANCO DO BRASIL}

Foi fundado em 1808 pelo príncipe regente D. João, quando o país passou a sediar a Coroa Portuguesa.

Em 1821, vinculou ao mercado de capitais brasileiro, sendo em 1905 o acionista majoritário o Governo federal e em 1906 com listagens publicas nas Bolsas de Valores.

Em 1945, foi responsável por pagar as tropas brasileiras, transferir numerário e atender à embaixada do país.

Em 1960, transferiu a sede para Brasília.

Em 1985 criou a fundação Banco do Brasil e inaugurou o Centro Cultural Banco do Brasil um ano depois. Lançou o portal na internet em 2000 e 2002 adequou o estatuto social para adoção e transparência das práticas sociais e 2011 fez aquisição do Banco da patagônia.

E em 2014 fez a revisão de sua missão, visão e valores de sua estratégia corporativa com o princípio de ser um banco de mercado com espírito público.

Hoje é um banco com maior atendimento no país e exterior, possuindo $99,8 \%$ nos municípios e 60,1 mil pontos de atendimentos e em 135 países com acordos em outros bancos hoje é controlada pela União desde 2006 no mercado BM\&F Bovespa.

\section{C.E.F. (CAIXA ECONÔMICA FEDERAL)}


Fundada em 1861 por D. Pedro II, denominada Caixa Econômica da Corte, com proposito de incentivar a poupança e conceder empréstimos sob penhor, com garantia do governo.

Em 1931, inaugurou as operações de empréstimo sob consignação para pessoas físicas onde depois assumiu a exclusividade desta atividade.

Em 1886, o banco incorporou ao BNH, Banco Nacional de Habitação, na qual foi a maior agente de financiamento de casa própria, desenvolvimento urbano e saneamento básico. Extinguindo-se o BNH no mesmo ano, tornou-se o principal Sistema Brasileiro de Poupança e Empréstimo (SBPE), administrando o FGTS e fundos do Sistema Brasileiro de Habitação na onde em 1990 iniciou a centralização de das contas de FGTS de 70 instituições bancárias. Em 1961 criou as Loterias federais, 1969 se tornou uma empresa pública com suas obrigações e deveres de natureza social e em 2013 iniciou iniciativas artísticas, culturais, educacionais e desportistas no Brasil.

Hoje é consolidada no mercado como grande porte, principal agente das políticas públicas do governo federal. Tem 62.406 pontos espalhados no Brasil, 2 agencias barcos e está em mais de 20 países.

\section{ANÁLISE DO BALANÇO SOCIAL DAS EMPRESAS}

O Balanço Social dos dois bancos foram analisados de forma comparativa entre os anos de 2013 e 2014. O Relatório Anual de Sustentabilidade e Balanços sociais publicados pelos bancos pode ser acessado no site de cada um que demonstram suas ações e investimentos em detalhes, contendo as fontes de informações referentes ao desenvolvimento de suas atividades sociais no contexto interno e externo, relevantes ao exercício da cidadania, sendo publicados anualmente com demonstrações contábeis do mesmo período.

$\mathrm{Na}$ sequência são analisados os dois Balanços Sociais, comparando-se os indicadores divulgados nos anos de 2013 e 2014. 
Tabela 1 - Comparativo do balanço social de 2013 e 2014 das instituições Banco do Brasil e Caixa Econômica Federal

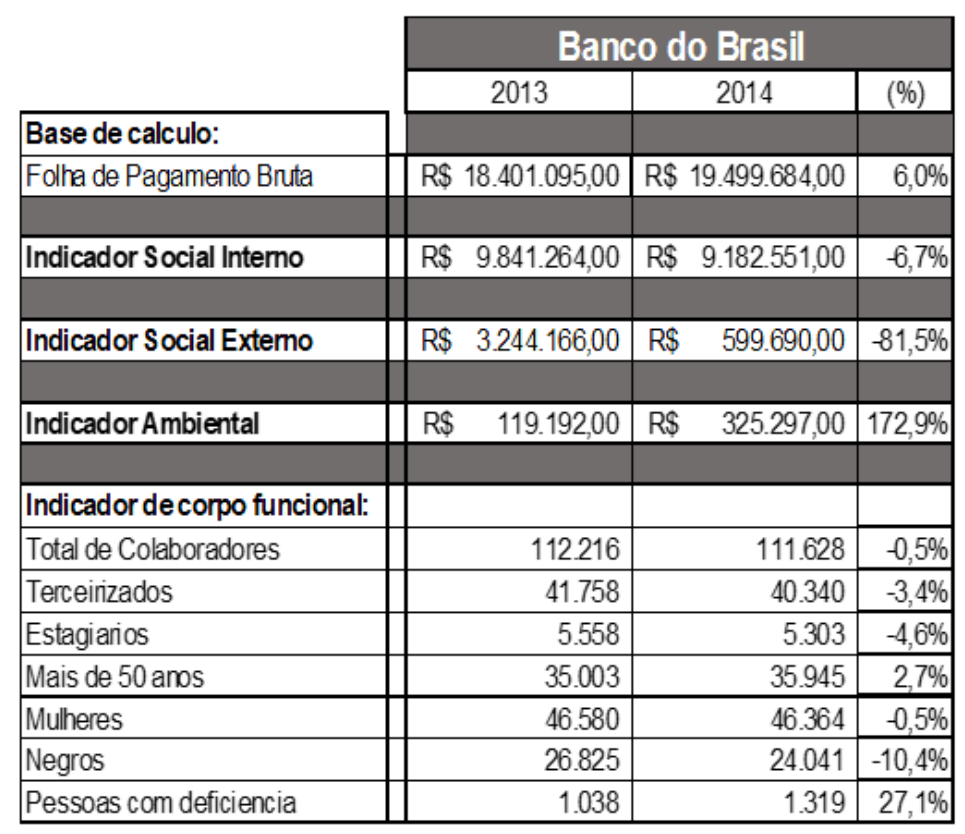

\begin{tabular}{|c|c|c|}
\hline \multicolumn{3}{|c|}{ Caixa Economica Federal } \\
\hline 2013 & 2014 & $(\%)$ \\
\hline $\mathrm{R} \$ 11.152 .423,00$ & $\mathrm{R} \$ 12.355 .653,00$ & $10,8 \%$ \\
\hline $\mathrm{R} \$$ & $\mathrm{R} \$$ & \\
\hline $\mathrm{R} \$$ & $\mathrm{R} \$$ & \\
\hline $\mathrm{R} \$ \quad 182.958,00$ & $\mathrm{R} \$ \quad 185.405,00$ & $1,3 \%$ \\
\hline & & \\
\hline 164.300 & 168.203 & $2,4 \%$ \\
\hline 48.946 & 51.553 & $5,3 \%$ \\
\hline 12.273 & 11.727 & $-4,4 \%$ \\
\hline 48.117 & 22.784 & $-52,6 \%$ \\
\hline 55.674 & 85.375 & $53,3 \%$ \\
\hline 36.458 & 38.165 & $4,7 \%$ \\
\hline 1.972 & 2.170 & $10,1 \%$ \\
\hline
\end{tabular}

Fonte: Dados de Pesquisa

\section{BASE DE CÁLCULO}

Referente ao Tabela 1, de 2013 para 2014, a folha de pagamento do Banco do Brasil aumentou 6\%, enquanto o banco Caixa foi de $11 \%$ a mais, entre 2013 e 2014

\section{INDICADORES SOCIAIS INTERNOS}

O Banco do Brasil, diminuído seus investimentos do indicador social interno em 6,7\% foi a menor diminuição comparado ao indicador social externo.

A Caixa Econômica, pesquisada, não disponibilizou informações totais ou com fácil identificação, não podendo ser comparado no ano ou com outra instituição.

\section{INDICADORES SOCIAIS EXTERNOS}

De 2013 a 2014 teve a diminuição de investimento em indicadores sociais 81,5\%, percebendo que o foco foi na importância do fator ambiental, relacionado este, ao 
Banco do brasil. A Caixa Econômica Federal não está disponibilizada as informações relativas a este Indicador de pesquisa.

\section{INDICADORES AMBIENTAIS}

Conforme demonstrado nas informações do Balanço Social respectivo, o Banco do Brasil dando ênfase no âmbito social, aumentou seu indicador a 173\%, diferente do Caixa, que foi apenas $1 \%$, mantendo a média no período comparado.

\section{INDICADORES DE CORPO FUNCIONAL}

O número total de colaboradores neste período teve diferença distinta entre cada empresa, sendo a diminuição de $0,5 \%$ no Banco do Brasil e aumento de $2,4 \%$ na Caixa Econômica.

Os funcionários terceirizados e prestadores de serviços tiveram diminuição de 3,4\%, enquanto no outro banco, acréscimo de 5,3\%.

As vagas de estagiários, tiveram diminuição com números próximos, de 4,6\% comparado com número de 4,4\%.

Funcionários com mais de 50 anos, o aumento de 2,7\% no Banco do Brasil, é comparado com diferença considerável na diminuição de $52,6 \%$ das vagas na Caixa Econômica.

Em relação ao número de mulheres na empresa, houve a diferença negativa de 0,5\%, e com diferente proporção, de 53\% a mais do que 2013.

Os negros tiveram grande queda de $10 \%$ no primeiro banco e no outro, acréscimo de $5 \%$.

Pessoas com deficiência, foi teve maior importância para o Branco do Brasil, com o aumento de $27 \%$ e $10 \%$ no Caixa. 
Ao analisar o tema de diversidade, a Caixa Econômica Federal tem o número maior do que Banco do Brasil de funcionários, sendo os negros em maior número, tendo a diferença de 14.124 funcionários, junto com as mulheres que tem quase a metade com 39.011 funcionários e portadores de deficiência com 1.132 funcionários. Diferente dos que tem mais de 50 anos que se diferenciam com 13.161 funcionários a menos.

\section{CONSIDERAÇÕES FINAIS}

Nesta pesquisa, nota-se um profundo conhecimento de sustentabilidade e responsabilidade social, referindo-se ao conceito e processo histórico da pesquisa técnica, analisando a forma que as empresas empregam suas ações na sua política corporativa, visando benefícios para colaborar com a sociedade e o meio ambiente, quanto na geração de valores aos investidores e acionistas.

Sobre as empresas analisadas, verifica-se que entre elas tem projetos em diversas áreas sociais, atuando internamente e externamente.

Encontra-se informações sobre responsabilidade social da empresa em seu próprio site, que divulgam seus balanços sociais referentes a seus indicadores.

Também se percebe que o balanço social em cada uma delas demonstra transparência com suas informações, podendo as vezes ser muito detalhada dificultando a análise.

\section{REFERÊNCIAS BIBLIOGRÁFICAS}

ALEMANDRO, Thiago. Empresas modelo $X$ empresas não modelos de responsabilidade social: um estudo comparativo de indicadores econômico e financeiros no período de 2001 a 2004. 2006. 48f. Tese. Disponível em: <http://www.fucape.br/premio_excelencia_academica/upld/

trab/9/thiago_alemandro.pdf>, Acesso: 19/10/2016 
ADCE/UNIAPAC BRASIL. Carta de princípios do dirigente cristão de empresa. Salvador, 1965.

ASHLEY, Patrícia Almeida (coord.). Ética e Responsabilidade social nos negócios. São Paulo: Saraiva, 2002.

ATKWHH, Instituto. As metas do milênio da ONU Disponível em: <http://www.institutoatkwhh.org.br/compendio/?q=node/19>. Acesso em: 18/10/16

BRASIL, Banco do. Balanço social 2014. Disponível em:

<http://www45.bb.com.br/docs/ri/ra2014/pt/11.htm>. Acesso em: 17/10/16

BNDES. Balanço da implementação da PRSA 2015-2017. Disponível em: <https:/www.bndes.gov.br/wps/wcm/connect/site/06130b22-68a44a85-b5be-731cbe6dc931/Relatorio_PRSA_20152017. pdf?MOD=AJPERES\&CVID=meElwW3>. Acesso: $29 / 11 / 17$

CAIXA ECONOMICA FEDERAL, Banco. Balanço Social 2014. Disponível em: $<$ http://www.caixa.gov.br/Downloads/caixa-relatoriosustentabilidade/Relatorio_de_Sustentabilidade_2014.pdf>. Acesso em:17/10/16

CAIXA ECONOMICA FEDERAL. Sobre a Caixa econômica federal. Disponível em: <http://www.caixa.gov.br/sobre-a-caixa/Paginas/default.aspx>. Acesso em: 29/10/16

CONSULTORIA, Dialogus. Abordagem histórica da responsabilidade social. Disponível em: $<$ http://www.dialogusconsultoria.com.br/novosite/index.php/artigo/uma-abordagemhistoricadaresponsabilidade-social>. Acesso:18/10/2016

DALBERIO, Osvaldo; DALBERIO, Maria Cecília Borges. Metodologia Científica: desafios e caminhos. São Paulo: Paulus, 2009. 
ETHOS, Instituto. Balanço social e a comunidade da empresa coma a sociedade Disponível em: <http://www3.ethos.org.br/wpcontent/uploads/2014/05/

O_Bal_Soc_e_a_Comun_da_E mpr_com_a_Soc_5edi.pdf>.

Acesso em: 18/11/2016

FIGUEIREDO, Nébia Maria Almeida de (org.). Método e metodologia na pesquisa científica. 2ª edição. São Caetano do Sul, SP: Yendis Editora, 2007.

FISCHER, Rosa Maria \& FALCONER, Andres Pablo. Voluntariado empresarial estratégias de empresas no Brasil. Revista de Administração da USP (RAUSP), v.36, n.3, p.5, julho. /setembro 2001.

FREIRE, F.S.; SILVA, C.A.T. (Org.) Balanço Social: teoria e prática. São Paulo: Atlas, 2001.

IBASE. Balanço social. Disponível em: <https://ibase.br/pt/balanco-social/>. Acesso em: 18/11/2016.

IBGE. Estimativa de população. Disponível em: <https://ww2.ibge.gov.br/home/estatistica/populacao/estimativa2016/estimativa_tcu.s htm>. Acesso: 18/10/16.

LUCA, Márcia Martins Mendes. Demonstração do Valor Adicionado. São Paulo: Atlas, 1998.

MARTINS, José Pedro Soares; Responsabilidade social corporativa: como a postura responsável pode gerar valor. São Paulo: Komedi,2008

NOVAES, Washington. Eco-92: avanços e interrogações.1992. 15f. Artigo-São Paulo,1992

OLIVEIRA, Marco Antônio L. de; AS 8000: o modelo ISSO 9000 aplicado à responsabilidade social. Rio de Janeiro: Qualitymark, 2002. 
PNUD. Objetivos do desenvolvimento sustentável.

Disponível em: <http://www.br.undp.org/content/brazil/pt/home/sustainabledevelopment-goals.html> Acesso:17/10/16

SAl. Norma SA8000. Disponível em:

$<\quad$ http://www.sa-intl.org/_data/global/files/SA8000Standard_Portugues(1).pdf >. Acesso: 11/03/19

SEVERINO, A. J. Metodologia do trabalho científico. 23. ed. rev. eatualizada. São Paulo: Cortez, 2007.

TENÓRIO, F. G. Responsabilidade social empresarial: teoria e prática: Rio de Janeiro: FGV, 2006.

UFSC. Responsabilidade social: estudo comparativo de duas instituições financeiras Disponível em: <http://dvl.ccn.ufsc.br/congresso/anais/1CCF/20090727165027.pdf>, Acesso em:19/10/2016.

UNDP. Brasil. Disponível em:

<http://www.br.undp.org/content/brazil/pt/home/countryinfo.html>. Acesso: 27/11/16

Enviado: Março, 2018.

Aprovado: Maio, 2019. 